\title{
40 Anos de Contribuição à Avaliação Educacional*
}

\author{
SANDRA ZÁKIA SOUSA \\ Professora da Faculdade de Educação da Universidade de São Paulo \\ sanzakia@usp.br
}

\begin{abstract}
Resumo
Este texto tem o propósito de caracterizar, em suas linhas gerais, as produções dos pesquisadores da Fundação Carlos Chagas acerca do tema avaliação educacional, abrangendo o período de 1972 a 2003. Essas produções abarcam desde avaliação de rendimento escolar até de sistemas educacionais, passando por material instrucional, projetos, programas e políticas educacionais, além de textos que se voltaram a questões conceituais, sociopolíticas e/ou metodológicas a respeito de medida e avaliação educacional. Essas produções foram demarcadas em seu percurso histórico, destacando seus focos mais expressivos e procurando estabelecer relações com a trajetória de produção de conhecimento em avaliação educacional no país.

Palavras-chave: avaliação, avaliação da aprendizagem, avaliação de projetos e programas; avaliação - questões metodológicas.
\end{abstract}

\section{Resumen}

El artículo busca caracterizar, en líneas generales, las producciones de investigadores de la Fundación Carlos Chagas acerca del tema Evaluación Educativa de 1972 a 2003. Además de artículos sobre cuestiones conceptuales, sociopolíticas y/o metodológicas respecto a la medida y evaluación educativa, esos trabajos abarcan todo tipo de evaluación: desde el rendimiento escolar hasta los sistemas educativos, pasando por materiales de instrucción, proyectos, programas y políticas educativas. Esas producciones han sido localizadas en su recorrido histórico, puntualizando sus aspectos más expresivos y tratando de relacionarse con el conocimiento en evaluación educativa del país en su trayectoria de producción..

Palabras-clave: evaluación, evaluación de aprendizaje, evaluación de proyectos y programas, evaluación - cuestiones metodológicas.

\footnotetext{
* Transcrito de Albertina de Oliveira Costa, Angela Maria Martins, Maria Laura Puglisi Barbosa Franco (orgs.) Uma História para contar: a pesquisa na Fundação Carlos Chagas. São Paulo: ANNABLUME, 2004. p. 173-202.
} 


\begin{abstract}
The purpose of this article is to broadly characterize the production of researchers at the Fundação Carlos Chagas on the topic of educational assessment over a 40-year period, from 1972 to 2003. These writings encompass a variety of areas, assessing from school progress to educational systems, through instructional materials, educational projects, programs and policies, in addition to texts that addressed conceptual, sociopolitical and/or methodological issues related to educational measurement and assessment. These papers have been identified as to their historic place, highlighting their most expressive points and attempting to establish relationships with the overall production concerning educational assessment in Brazil.
\end{abstract}

Key words: assessment, learning assessment, assessment of projects and programs, assessment - methodological issues 
Comentar as produções dos pesquisadores da Fundação Carlos Chagas acerca do tema avaliação educacional é uma tarefa que remete a considerações desde a própria origem da instituição até à trajetória da produção de conhecimento sobre o tema, no Brasil. Recebi o convite para realizar tal tarefa, por um lado, com muita satisfação, já que se trata de assunto ao qual há muito dedico meus estudos, que tiveram, em seu início, impulso dado pela oportunidade de exercer a função de auxiliar de pesquisa em uma das equipes da Fundação, que realizava, à época, avaliação de programas educacionais. Por outro, com muita apreensão, quanto a reunir as condições para analisar tão expressiva e extensa produção.

Análises, discussões e propostas sobre aspectos ligados à avaliação educacional são foco de 259 títulos de autoria de pesquisadores da Fundação Carlos Chagas, identificados em levantamento disponibilizado pela Biblioteca Ana Maria Poppovic, da Fundação, para elaboração deste texto. Abrangendo o período de 1972 a 2003, abarca 10 livros, 18 capítulos de livros, 163 artigos, 64 relatórios técnicos de pesquisa, 3 teses e 1 dissertação. Quanto aos artigos, a maior parte (144) foi publicada em periódicos editados pela própria Fundação Carlos Chagas, quais sejam, Cadernos de Pesquisa, que tem seu primeiro número editado em 1971, com divulgação ininterrupta até os dias de hoje e Estudos em Avaliação Educacional, iniciado em 1990, dando continuidade à revista anteriormente denominada Educação e Seleção, publicada ao longo de dez anos, de 1980 a 19891.

Nessas produções, diferentes foram os objetos focalizados nas iniciativas, pesquisas e projetos desenvolvidos e divulgados pela Fundação Carlos Chagas, abarcando desde avaliação de rendimento escolar até de sistemas educacionais, passando por material instrucional, projetos, programas e políticas educacionais, além de textos que se voltaram a questões conceituais, sociopolíticas e/ou metodológicas acerca de medida e avaliação educacional.

Com o propósito de caracterizar em suas linhas gerais essa produção, a opção foi demarcá-la em seu percurso histórico, destacando seus focos mais expressivos e procurando estabelecer relações com a trajetória de produção de conhecimento em avaliação educacional no país,

1 A relação de textos do Departamento de Pesquisas Educacionais da Fundação Carlos Chagas, sobre avaliação educacional, publicados nas revistas Cadernos de Pesquisa (19712004), Educação e Seleção (1980-1989) e Estudos em Avaliação Educacional (1990-2004), está publicada no n. 29 de Estudos em Avaliação Educacional. 
contando, para isso, com as contribuições de alguns dos próprios autores da Fundação Carlos Chagas. Dentre essas contribuições, tem-se aquelas que se voltam a uma retrospectiva histórica da avaliação educacional no Brasil, destacando-se as de Vianna (1992, 1995), Gatti (1994), Sousa (1998) e Barretto e outros (2001).

Os escritos de Vianna, Gatti e Sousa são expressão de autores que há muito têm se dedicado à investigação na área da avaliação educacional e que, ao tecerem uma retrospectiva da produção nacional, o fazem a partir do resgate de sua própria vivência.

A pesquisa de Barretto e outros se refere a uma análise da produção acadêmica sobre avaliação da educação básica, no período 1990 a 1998, tendo como fonte artigos divulgados em periódicos de expressão nacional, identificando tendências e características do conhecimento que vem sendo produzido na área.

\section{SELEÇÃO E MEDIDA EDUCACIONAL - A ORIGEM DA FUNDAÇÃO CARLOS CHAGAS}

Falar da origem da Fundação é retomar, mesmo que sucintamente, os moldes como se realizavam os exames vestibulares no início da década de 1960. A cargo das faculdades, nomeavam-se comissões de professores que se responsabilizavam, em cada uma delas, pelo planejamento e execução do exame para seleção dos candidatos. Em 1963, algumas faculdades, por meio de seus professores e dirigentes, decidiram pela realização de exames conjuntos na área de biológicas, sendo criado, em 1964, o Centro de Seleção de Candidatos às Escolas Médicas (CESCEM)².

Para realização do vestibular com aporte de especialistas em medida educacional e recursos tecnológicos que atendessem adequadamente as exigências de preparação, organização e execução do processo seletivo para ingresso no ensino superior, foi criada a Fundação Carlos Chagas, em novembro de 1964, instituição responsável pela gestão do conjunto de atividades inerentes ao exame. Ocupando um lugar pioneiro no desenvolvimento de processos seletivos para cursos superiores, a Fundação inspirou outras iniciativas e, até mesmo, organização de outras instituições, em âmbito estadual e nacional, direcionadas à realização de concursos vestibulares.

A revista Educação e Seleção (1980-1989), editada pela Fundação Carlos Chagas, traz informações e reflexões sobre questões relativas à

2 Sobre as origens do vestibular unificado, ver Leser (1985). 
seleção para cursos superiores que permitem uma incursão pela trajetória de processos seletivos e medida educacional, no Brasil. Aliás, a publicação da revista, conforme consta da apresentação de seu primeiro número, visou "a promover o intercâmbio de informações, a estimular a reflexão e investigação sobre problemas de seleção, a pôr, enfim, mais aclaradamente as múltiplas faces do processo seletivo" (Sanchez, 1980). Esta revista se modificou ao longo dos anos, dando origem a uma nova publicação intitulada Estudos em Avaliação Educacional, editada a partir de 1990, a qual dá continuidade à divulgação de estudos relativos ao processo de seleção para a Universidade, mas ocupa-se, também, "de problemas ligados à avaliação do rendimento escolar nos vários níveis de ensino, à avaliação de currículos, à avaliação de material didático, à avaliação de cursos, à avaliação de professores, à avaliação de instituições e, inclusive, à avaliação de sistemas, no contexto da educação brasileira" (Apresentação, 1990).

As atividades da Fundação Carlos Chagas relativas a processos seletivos, inicialmente direcionados ao acesso ao ensino superior, ampliaram-se para outros segmentos e setores, preponderantemente da área educacional, atendendo a demandas de órgãos governamentais e instituições privadas.

Lembrar a origem da Fundação significa datar o momento em que se intensificam no país os estudos e pesquisas acerca de medida educacional. Como diz Heraldo Vianna:

"Quando se considera a evolução histórica da avaliação educacional no Brasil, observa-se que a utilização de testes, entendidos como provas do tipo objetivo, somente adquire algum significado e passa a exercer alguma influência a partir de meados da década de 60. Anteriormente a essa época, a aplicação de testes objetivos de escolaridade constituía rara exceção e resultava, na maioria das vezes, do esforço experimentalista de elementos isolados, geralmente influenciados pela literatura pedagógica norte-americana, que, no após-guerra, passou a exercer considerável influência na vida educacional brasileira, substituindo a francesa, que dominara a cultura do Brasil a partir do século XIX. (...) O uso do teste em larga escala está associado, no contexto educacional brasileiro, ao ingresso nas universidades, que, na década de 60, começou a sofrer pressões de grandes massas de candidatos para um número reduzido de vagas." $(1978$, p.69)

Ou, como comenta Bernardete Gatti:

“O uso de testes educacionais de modo mais generalizado se deu no Brasil a partir de meados da década de 60. Seu emprego em nosso meio está muito associado a exames vestibulares, através dos quais esta maneira de avaliar conseguiu ampla divulgação. É, também, neste período que uma perspectiva mais tecnicista e 
economicista começa a dominar na área educacional, principiando a proliferação de textos mais específicos sobre medidas educacionais, nos quais se discutem as técnicas de elaboração das chamadas questões e provas objetivas e as questões estatísticas envolvidas na teoria das medidas." (1987a, p34)

Assim, o significado inicial atribuído à expressão avaliação educacional, em estudos divulgados, tratava, de modo dominante, de medida educacional, explorando perspectivas diversas, que abrangiam desde a elaboração de instrumentos de medida, critérios para julgamento de sua validade e fidedignidade, até análises de relações entre desempenho em testes e variáveis de indivíduos ou grupos. Especialmente nas décadas de 1970 e meados da de 1980 foram socializados, por meio das revistas editadas pela Fundação, aportes teóricos e metodológicos em medidas educacionais, em sua maior parte oriundos das atividades direcionadas a processos seletivos, registrando-se, também em 1973, a edição do livro Testes em Educação, de Heraldo Vianna (1973), que apresenta a teoria clássica das medidas educacionais.

É interessante observar que no início da década de 1980 começa a se explicitar, nos textos que tratam de medida educacional, uma diferenciação das noções de medida e avaliação. É ilustrativo nesse sentido observarmos "convivendo", em um mesmo número da revista Educação e Seleção, tanto o tratamento da medida como sinônimo de avaliação quanto a preocupação em diferenciação destes conceitos. Sob o título "Considerações sobre avaliação educacional", Ribeiro Netto inicia o artigo afirmando:

"Avaliação é o processo de medida do comportamento de uma ou mais variáveis numa população definida, em condições especificadas de tempo e de espaço. Quando a variável ou variáveis dizem respeito à educação, fala-se em avaliação educacional." (1982, p.5)

Nesta mesma revista, Vianna, em artigo intitulado "Avaliação educacional - problemas gerais e formação do avaliador", comenta que medir e avaliar são expressões freqüentemente usadas como intercambiáveis, no entanto:

"Medir é uma operação de quantificação, em que se atribuem valores numéricos, segundo critérios preestabelecidos, a características dos indivíduos, para estabelecer o quanto possuem das mesmas. (...) Relativamente à avaliação, a medida é um passo inicial, às vezes bastante importante, mas não é condição necessária, e nem suficiente, para que a avaliação se efetue. Eventualmente, a 
medida pode levar à avaliação, que, entretanto, só se realiza quando são expressos julgamentos de valor." (1982, p.10)

Essa diferenciação, explicitada nessas referências, abre, no Brasil, uma nova perspectiva conceitual, alargando os horizontes e finalidades da avaliação educacional.

Embora com ênfase em aspectos técnicos de medidas educacionais, refletindo o próprio momento da pesquisa educacional no Brasil, que se voltava para a mensuração de habilidades e aptidões de alunos, é oportuno registrar que, dentre as produções dos pesquisadores, há aquelas que contemplam questionamentos que não perderam a atualidade, como quando Carmen Barroso, em apresentação de seu artigo, problematiza, dentre outros aspectos, os critérios de seleção de candidatos às universidades, lembrando que, ao lado da eficiência, o critério de justiça mereceria ser considerado. Menciona as iniciativas ainda incipientes, à época, que vinham sendo tomadas por universidades norte-americanas, comentando:

\footnotetext{
"Tentativas inovadoras deslocam a ênfase exclusiva na eficiência, e passam a englobar um conceito mais amplo de justiça, que implica o reconhecimento de que o indivíduo não pode ser inteiramente responsabilizado pelo seu estado de desenvolvimento atual. Assim, na seleção, procura-se identificar, não apenas os mais aptos e mais promissores, mas também os indivíduos que, por suas condições reais de existência, como participantes de minorias, não tiveram oportunidade de alcançar níveis mais altos de realização intelectual, assim como os indivíduos cujas características pessoais mais marcantes diferem das que são comumente exigidas pelo mercado de trabalho. É óbvio que estas tendências não chegam a constituir característica dominante no sistema educacional, o qual continua basicamente meritocrático." (1973, p.55)
}

Quando se discute hoje a implantação, para ingresso em universidades brasileiras, do sistema de cotas para dados segmentos da população, o que está em questão são os critérios vigentes de seleção, tal como problematizava Barroso há mais de trinta anos.

\section{OUTRAS TENDÊNCIAS IDENTIFICADAS NA PRODUÇÃO}

A partir da constatação da origem e característica dominante das produções inicialmente desenvolvidas pela Fundação, direcionadas para testes e medidas de desempenhos, preponderantemente para processos 
seletivos, identificam-se duas tendências de estudos e pesquisas que ganham igual visibilidade no conjunto da produção, nestes quarenta anos:

- concomitantemente ao desenvolvimento de estudos acerca de testes e medidas educacionais, desde os anos iniciais da década de 1970, há produções que se direcionam à avaliação de projetos e programas educacionais, assumindo, inicialmente, características mais próximas da área de avaliação de currículo e, posteriormente, dos anos 90 em diante, são objeto da avaliação projetos que integram dadas políticas educacionais; $\mathrm{e}$,

- a partir dos anos iniciais da década de 80, são desenvolvidos estudos sobre avaliação de rendimento escolar de alunos, atendendo a propósitos diversos, como se procurará caracterizar mais adiante, podendo tal produção, em sua maior parte, ser caracterizada como uma continuidade, embora com novas perspectivas e abrangência, do desenvolvimento de testes e medidas educacionais.

Seguem-se considerações sobre tais estudos e pesquisas, que, frente às suas especificidades, serão tratados separadamente.

\section{SOBRE AVALIAÇÃO DE PROJETOS E PROGRAMAS EDUCACIONAIS}

Inseridos no campo da avaliação de currículo, os trabalhos coordenados por Maria Amélia Goldberg, a partir dos anos iniciais da década de 70, expressam um momento significativo da produção e divulgação de conhecimento na área da avaliação educacional no Brasil. Concebendo-se a avaliação como atividade inerente ao processo de planejamento educacional, esta é assim definida em artigo que pode ser tomado como referência para ilustrar o papel atribuído à avaliação:

"Na medida em que a unidade do processo de planejamento educacional é garantida pelo plano, testar a racionalidade daquele é procurar determinar a racionalidade das decisões que geraram o plano e das ações que ele produziu. A racionalidade nas decisões confere ao plano sua dimensão de eficácia enquanto que a racionalidade na execução the confere a dimensão de eficiência. Eficácia e eficiência são duas dimensões absolutamente indispensáveis ao modelo de um programa educacional válido. No trocadilho inteligente de Peter Drucker, não basta 'fazer certo as coisas': é preciso 'fazer as coisas certas'. Eis porque ambas 
precisam ser avaliadas e eis porque podemos conceituar avaliação educacional como $o$ processo de coletar, analisar e interpretar evidências relativas à eficácia e eficiência de programas educacionais." (1973, p.65)

$\mathrm{O}$ que se nota nos estudos e pesquisas realizados e divulgados a partir desta concepção de avaliação é tomar-se como foco para avaliação educacional o currículo escolar, concretizado em programas educacionais e não os alunos individualmente. São ilustrativos nessa direção os estudos divulgados em artigos e livros organizados por Maria Amélia Goldberg, em conjunto com Clarilza Sousa $(1979,1982)$ e com Maria Laura Franco (1980), no que se referem aos projetos de avaliação desenvolvidos, relativos a avaliações de inovações curriculares e programas de ensino.

Os textos de divulgação acerca dos estudos desenvolvidos evidenciam rigor conceitual e metodológico, sendo as indicações, conclusões e recomendações amparadas pelo conjunto de informações trazidas pela avaliação. É clara a preocupação em se explicitar a abordagem ou modelo de avaliação assumido nessas produções.

$\mathrm{Na}$ produção direcionada a programas educacionais, identificada nesse período, as referências bibliográficas utilizadas evidenciam a apropriação de abordagens avaliativas de autores estrangeiros, que se constituem, até hoje, referências para o desenvolvimento de projetos avaliativos. Elba Barretto e outros, ao comentarem a nova dimensão metodológica dada à avaliação, no Brasil, após 1970, destacam:

"Os referenciais adotados à época apontam para a necessidade de levar em conta o grande número de variáveis presentes nos programas educacionais e atuar no campo em que os atores sociais naturalmente se movem, buscando superar designs de 'controle', amplamente utilizados na pesquisa experimental ou quaseexperimental de base psicológica.

Tais transformações transitam pela preocupação da avaliação voltada para a tomada de decisões, como em Stufflebeam; pela avaliação responsiva de Stake, a qual se orienta mais para as atividades do programa do que para as intenções por ele declaradas; pelo flexionamento feito por Scriven, que passa da defesa de uma avaliação centrada em objetivos à necessidade de não separar os fins dos efeitos secundários e sociais de um programa. Os enfoques caminham também pela avaliação iluminativa de Parlett e Hamilton, proposta na Inglaterra; pela observação participante e pela pesquisa-ação." (2001)

É ilustrativa dessa análise a descrição de Clarilza Sousa apresentada em artigo que resgata a trajetória da avaliação educacional no Brasil a partir da própria vivência da autora nesse campo de investigação, quando afirma: 


\begin{abstract}
"Até a década de 70, quando comecei a trabalhar com a avaliação, as concepções presentes em toda a área educacional tinham como suporte um paradigma positivista e eram fortemente orientadas pela produção de avaliadores norteamericanos. Avaliar consistia em comparar os resultados dos alunos com aqueles propostos em determinado plano. (...) Neste período, em conjunto com os avaliadores brasileiros que também rejeitavam a orientação teórica predominante da avaliação educacional, fomos buscar fundamentos em autores como Michael Scriven, Robert Stake, Daniel Stufflebeam, David Hamilton, Malcom Parlett, Barry MacDonald." (1998, p.162-163)
\end{abstract}

Usualmente, os estudos que têm se voltado para uma retrospectiva da produção em avaliação educacional no Brasil - Sousa, 1994; Barretto et al., 2001 -, apoiados na própria trajetória da pesquisa em educação Orlandi, 1969; Gouveia, 1971; Cunha, 1979; Gatti, 1987, Vianna, 1995 -, têm caracterizado a produção dos anos 70 e anos iniciais da década de 80 como respaldada em pressupostos positivistas, que se expressam em um tratamento da avaliação como mecanismo de controle do planejamento, sob a crença de que a maior produtividade do sistema de ensino seria alcançada pela via da racionalização do trabalho, sem qualquer interesse em se questionar os princípios estruturantes do currículo, bem como suas relações com a sociedade, desconsiderando-se os conflitos e relações de poder presentes na sociedade capitalista. Como conseqüência, a avaliação é tratada com atividade técnica, dissimulando-se sua dimensão política e ideológica.

Ao reler os relatos de avaliações produzidos por pesquisadores da Fundação Carlos Chagas, no âmbito do que delimitei como avaliação de currículo, evidencia-se que, ao lado do rigor metodológico, estava presente a consciência de que as dimensões valorativas e políticas são inerentes ao fenômeno educacional, e, em decorrência, à avaliação educacional.

Para além de se destacar a avaliação como medida da eficiência de um dado programa, expressa na produtividade de sua operação e efetividade na produção de resultados, é destacado o conceito de eficácia, que significa avaliar se o programa responde a necessidades sociais legítimas. Embora no delineamento dos projetos não se contemple a discussão dessas necessidades e sua eventual legitimidade para diferentes grupos e setores da sociedade, é possível identificar, a partir do início dos anos de 80 , a presença da afirmação da dimensão política da avaliação, como pressuposto de trabalho.

Nessa perspectiva, registra-se a publicação da revista Educação $e$ Avaliação, editada sob a liderança de Maria Amélia Goldberg e Clarilza Prado de Sousa, pesquisadoras da Fundação Carlos Chagas, que é assim 
comentada por Ana Maria Saul ao referir-se à produção nacional relativa a avaliação de currículo:

\begin{abstract}
“(...) um conjunto mais completo de textos de autores brasileiros que criticam a abordagem quantitativa e apresentam alternativas qualitativas para a avaliação educacional surge com a edição dos dois primeiros números (infelizmente únicos) da revista Educação e Avaliação, publicados respectivamente em 1980 e 1981. Essa revista teve, ainda, o mérito de incluir artigos de autores nacionais que analisavam e discutiam dimensões da avaliação educacional até então ausentes na literatura da área. Essas dimensões referiam-se principalmente a aspectos políticos da avaliação educacional e à avaliação como via de intervenção social." (1988, p. 40)
\end{abstract}

Evidencia-se, nas produções lideradas por Maria Amélia Goldberg à época, a explicitação das dimensões política e técnica da avaliação, assim caracterizadas:

“a) política, porque só os ingênuos ou os de má fé, negam esta faceta à Educação e Avaliação;

b) técnica, porque não basta ao educador e ao avaliador ser um profissional crítico. É preciso ser competente, a fim de atingir os resultados que criticamente venha a perseguir." (Sanchez, 1980)

Também merece registro, a iniciativa de Goldberg e Sousa (1982) de traduzir e divulgar para os estudiosos da área, no Brasil, textos críticos, de autores estrangeiros, por meio do livro Avaliação de programas educacionais: vicissitudes, controvérsias, desafios, que tratam de questões conceituais, sociopolíticas e metodológicas da avaliação educacional, que se mantêm atuais.

Entretanto, embora trazendo importante contribuição para uma ampliação de perspectivas no campo da avaliação educacional, incorporando inclusive às reflexões a dimensão política da avaliação, a tendência observada nas análises de programas e projetos, divulgadas nas produções, evidencia o viés tecnicista, dominante à época nas investigações educacionais, "sendo que os estudos usualmente se limitam a aferir em que medida as metas de determinado programa estão ou não sendo alcançadas, sem entrar no mérito propriamente político do que está sendo avaliado" (Barretto et al., 2001, p.4).

$\mathrm{Ou}$, talvez, essa tendência dominante não tenha tido tempo de ser revertida e se traduzir em novas abordagens de pesquisa divulgadas acerca de avaliação de currículo por terem sido redirecionados os próprios objetos 
de avaliação a que se dirigiram os projetos de pesquisadores da Fundação ou até reorganizados os grupos de pesquisadores.

A partir da década de 90, a produção da Fundação relativa a avaliações de projetos e programas educacionais, preponderantemente, direciona-se a iniciativas desencadeadas no âmbito de políticas governamentais, visando analisar seus eventuais resultados e impactos. $\mathrm{Ou}$ seja, são objeto de avaliação programas ou projetos que se caracterizam como atividades específicas que se inserem no contexto de implementação de uma dada política pública de educação.

Tais pesquisas podem ser caracterizadas como avaliação de dadas facetas de políticas educacionais, mas, como nos estudos anteriormente comentados, não se propõem a uma avaliação política, ou seja, não direcionam seus questionamentos aos princípios e finalidades das iniciativas em análise, mas sim em seu desenvolvimento, resultados e impactos.

A produção relativa à avaliação de ações de governo intensifica-se, no Brasil, a partir do processo de transição democrática, nos anos 80 , tendo origem, por um lado, na "maior receptividade que as administrações públicas passaram a ter diante desse tipo de apreciação" e, por outro, em exigências de organismos multilaterais, cuja importância vem sendo crescente na definição e financiamento das políticas no setor, as quais incidem sobre as avaliações externas, realizadas por instituições não diretamente envolvidas com as políticas" (Barretto et al., 2001, p.77).

As avaliações de programas e ações de governo intensificam-se, na década de 1990, na medida em que a avaliação passa a ocupar papel central na formulação e implementação das políticas educacionais.

Na produção da Fundação Carlos Chagas, focalizam-se, em sua maior parte, programas educacionais desenvolvidos pela Secretaria de Estado da Educação de São Paulo, tais como: Jornada Única (Gatti, 1990); Projeto Cefam (Grosbaum et al., 1992); Escolas-Padrão (Esposito, Franco, 1992); Ciclo Básico (Davis, Esposito, 1992; Silva, Esposito, 1995; Esposito 1996); Projeto de Formação Continuada (Fundação Carlos Chagas, 1997, 1998); Avaliação de um programa de governo (Martins, 1999); Classes de Aceleração (Silva, 2000); Programa de Expansão e Melhoria do Ensino Médio no Estado de São Paulo - Promed (Fundação Carlos Chagas, 2003). Quanto a programas desenvolvidos pelo Ministério da Educação, registrase a avaliação do Programa “Um salto para o futuro" (Barretto, Pinto, 1997) 
e do Programa de Expansão e Melhoria da Educação no Meio Rural Edurural (Gatti, 1981, 1994; Davis, Dietzsch, 1983)3.

As avaliações de programas como as aqui mencionadas foram desenvolvidas, em sua maioria, em resposta a demanda de gestores públicos, decorrentes de exigências de acordos com organismos internacionais, que contemplam, dentre outras, a de avaliação do programa e/ou projeto objeto de financiamento.

As trilhas metodológicas percorridas nas avaliações de projetos e programas desenvolvidos no âmbito de políticas governamentais foram diversificadas. Tendo como propósito dominante, embora não exclusivo, cotejar finalidades e objetivos pretendidos e resultados obtidos, elas recorrem a procedimentos diversificados que abarcam desde levantamentos e análises de dados estatísticos, análise documental, avaliação de rendimento de alunos como indicador de resultados de dadas políticas e estudos de caso, de contextos escolares, visando apreender a concretização de determinados programas a partir de referenciais e condicionantes diversos.

Observando o conjunto da produção na vertente aqui denominada avaliação de programas e projetos, identifica-se, como já assinalado, uma mudança de foco: da avaliação de currículo para a avaliação de programas e projetos implementados no âmbito de políticas educacionais. Além disso, nos estudos na área curricular, evidencia-se a preocupação de se explicitar o referencial teórico-metodológico assumido nas avaliações, situando-o no contexto da literatura da área, tendo, ainda, algumas publicações, uma conotação não só informativa, mas formativa, aos eventuais leitores. A título de ilustrar essa preocupação, lembra-se que o livro $A$ prática da avaliação, de Goldberg e Sousa (1979), tem um dos capítulos dedicados ao treinamento para elaboração de plano de avaliação, ou o livro, de Goldberg e Franco (1980), em que são detalhadamente apresentadas experiências de avaliação realizadas no contexto brasileiro. É evidente o propósito, das autoras, de divulgar e debater os estudos e pesquisas desenvolvidas, face as publicações - artigos e livros - que são elaborados em curto espaço de tempo.

Nos estudos posteriores, relativos a avaliações de projetos e programas educacionais, desenvolvidos no âmbito de políticas governamentais o delineamento assumido é claramente apresentado, não se notando, no entanto, comparativamente às produções anteriores, a exploração dos fundamentos e princípios da abordagem assumida no

3 Por suas características, optou-se por tratar do Projeto de Avaliação do Programa Edurural no próximo item deste texto. 
desenvolvimento da avaliação. Talvez, tal constatação possa ser compreendida no movimento da produção de pesquisa em avaliação educacional no Brasil, quando, em decorrência de uma crítica à dimensão tecnológica da avaliação, com ênfase em seu caráter cientificista e nos métodos e procedimentos operacionais, a tendência é o desenvolvimento de estudos descritivos, combinando-se um enfoque qualitativo com uma análise de objetivos previstos e realizados, nos programas e projetos.

Ainda, há que se observar que os principais destinatários dessas avaliações são gestores públicos, que se espera venham se apropriar dos resultados das avaliações. Assim, os relatórios tendem a não privilegiar um aprofundamento acerca das opções teórico-metodológicas, mas, sim, informações potencialmente capazes de subsidiar decisões a respeito da continuidade ou redirecionamento de decisões e ações. Consideração nesse sentido é feita por Barretto et al. (2001, p.76) ao comentar sobre a pouca divulgação, em veículos de ampla divulgação, de resultados de avaliações de programas governamentais, que tendem a se restringir aos envolvidos com as decisões a serem tomadas.

\section{DA AVALIAÇÃO DE RENDIMENTO ESCOLAR À AVALIAÇÃO DE SISTEMAS EDUCACIONAIS}

Nos estudos desenvolvidos acerca da avaliação de rendimento escolar de alunos pode-se identificar diferentes perspectivas, embora relacionadas entre si, que se fazem presentes na produção analisada:

- uma delas, sobre o desenvolvimento de avaliações de rendimento de alunos, é realizada, em quase sua totalidade, em resposta às demandas governamentais, direcionadas a diferentes níveis de ensino, abrangendo disciplinas diversas, com o propósito de aferir o nível de desempenho apresentado por alunos em testes aplicados a uma amostra ou à totalidade da população estudantil, de um dado sistema de ensino;

- outra, como desdobramento e ampliação desta primeira perspectiva, refere-se à realização de avaliações de sistemas escolares ou avaliação em larga escala, incorporando à avaliação do rendimento escolar de alunos a análise de características que se fazem presentes nos contextos escolares, como fatores intervenientes no desempenho escolar, internos e externos à escola; 
- ainda, com produção menos expressiva em termos numéricos, tem-se estudos focalizados na análise e compreensão do desempenho escolar de alunos, à luz de condicionantes internos e externos à escola, discutindo a aprendizagem escolar no contexto de suas reais condições de produção.

Ao que parece, tendo em conta análises presentes em produções dos pesquisadores da própria Fundação, da perspectiva inicial de desenvolvimento de instrumentos de medida de rendimento escolar, desdobram-se, sob motivações diferentes, as duas outras abordagens, tendo como alvo aferir qualidade do ensino. Com tal compreensão, pretende-se aqui caracterizar essas perspectivas presentes nos textos, como movimentos de produção de conhecimento que coexistem na Fundação, mencionando algumas das atividades e reflexões desenvolvidas por seus pesquisadores.

Um marco no desenvolvimento de avaliação de rendimento escolar, como meio para aferir qualidade de ensino, recorrendo-se a procedimentos externos às escolas, foi o desenvolvimento do Projeto de Avaliação do Programa de Expansão e Melhoria da Educação no Meio Rural (Edurural/NE), executado com financiamento do Banco Mundial, em decorrência de acordo firmado com a União. Planejado para ser desenvolvido no período 1980-1985, em 250 municípios dos estados da região Nordeste do Brasil, tinha como objetivos centrais a ampliação do acesso à escola, da população em idade escolar; a maior eficiência dos processos de escolarização; e, melhor qualidade da educação, a ser traduzida, entre outros indicadores, em melhoria do rendimento escolar dos alunos atendidos pelo programa. A Fundação Cearense de Pesquisa, responsável pelo Projeto de Avaliação, voltado para uma análise do impacto das ações executadas, contou com a colaboração da Fundação Carlos Chagas, no delineamento e desenvolvimento deste Projeto, particularmente nos aspectos "concernentes ao rendimento escolar" (Gatti, Vianna, Davis, 1991, p.9).

Dentre as experiências mais abrangentes de avaliação do rendimento escolar, a do Edurural é a primeira realizada no Brasil (Gatti, 1993a, p.101), e "consistiu em um estudo transversal, com coleta de dados em uma amostra aleatória de 603 escolas em três Estados: Pernambuco, Piauí e Ceará", tendo sido testadas, em Língua Portuguesa e Matemática, "as crianças que freqüentavam as $2^{a}$ e $4^{a}$ séries do primeiro grau" (Gatti, 1993a, p.102).

Nessa experiência já se constata a combinação de procedimentos de medida de rendimento escolar e o desenvolvimento de estudos de caso. 
Visando apreender a escola rural em seu contexto, foram realizados "seis estudos de caso que, ao identificar as variáveis conjunturais que atuam no processo ensino-aprendizagem, iluminariam a compreensão do que se passa nas escolas rurais ao nível do desempenho dos alunos" (Gatti Vianna, Davis, 1991, p.10). Na produção analisada da Fundação Carlos Chagas, esses estudos de casos são divulgados por Gatti (coord., 1981) e Davis (1988).

Outro abrangente estudo de avaliação de rendimento escolar, demandado pelo Ministério da Educação, por meio do Instituto Nacional de Estudos e Pesquisas Educacionais (Inep), que contou com a colaboração da Fundação Carlos Chagas no desenvolvimento dos procedimentos de medida, ocorreu nos anos de 1987 a 1989. Consistiu na "avaliação de 27.455 alunos de 236 escolas, distribuídas em 69 cidades, localizadas nos vários Estados da Federação e em um Território4 (Amapá). As disciplinas abrangidas foram Português, Matemática e Ciências. As séries avaliadas foram as $1^{\mathrm{a}} \mathrm{s}, 3^{\mathrm{a}} \mathrm{s}, 5^{\mathrm{a}}$ s e $7^{\mathrm{a}}$ s do ensino fundamental" (Gatti, 1993a, p.104). Há outros estudos divulgados, como o que se realizou sob coordenação de Heraldo Vianna (1993), voltado à avaliação de um total de 5695 alunos do $1^{\circ}$ grau de escolas privadas, situadas em 12 capitais de estado, tendo sido utilizados os mesmos testes elaborados para aplicação com os alunos de redes públicas; e, ainda, a avaliação de rendimento escolar realizada no Estado do Paraná, divulgada por Heraldo Vianna e Bernardete Gatti (1988).

Estes estudos se constituíram em referência para participação da Fundação na primeira iniciativa do MEC de criação de um sistema nacional de avaliação da Educação Básica, em 1990. As provas de medida de rendimento escolar, utilizadas nesta avaliação foram as "mesmas elaboradas e validadas pela Fundação Carlos Chagas, nos estudos antes referidos" (Gatti, 1993a, p.111).

A participação da Fundação Carlos Chagas na elaboração de instrumentos de medida de rendimento escolar, ao que se evidencia em escritos de autores da Fundação, apóia-se na crença de sua importância para subsidiar melhorias no ensino e aprendizagem, como ilustra esta afirmação:

"O importante, em relação à atual estrutura do ensino em seus vários graus, é criar um sistema de avaliação externa que, de modo sistemático, informe aos responsáveis pelo ensino/educação os problemas da realidade pedagógica que ocorrem na escola e que se refletem nos diferentes níveis de capacitação cognitiva. A identificação de pontos críticos no desempenho escolar dos estudantes deve ser

4 O Território do Amapá foi transformado em Estado pela Constituição Federal de 1988. 
um dos objetivos do diagnóstico de conhecimentos, para que possam ser corrigidos os desvirtuamentos do processo ensino/aprendizagem." (Gatti, Vianna, Davis, 1991, p. 22)

A extensa experiência acumulada pela Fundação, desde a sua origem, na área de medida educacional resulta em sua participação em diversas iniciativas do Ministério da Educação, nos anos 1990, de organização de avaliações externas, por meio de provas de rendimento, direcionadas para diferentes níveis de ensino, como o Sistema Nacional de Avaliação da Educação Básica (Saeb), em 1990 e o Exame Nacional de Ensino Médio (Enem), em 1998, como indicam relatórios arrolados dentre suas publicações. Integrando esse movimento, merecem também destaque textos informativos acerca de fundamentos de medida educacional, particularmente aqueles que, para além da teoria clássica de medida educacional, informam sobre a teoria de resposta ao item (TRI), que passa a ser utilizada, particularmente no Saeb, em meados da década de 1990, para montagem de instrumentos, tratamento de dados e construção de escalas a partir de resultados apresentados por alunos em provas de rendimento (Fletcher, 1994, 1995; Andrade, Valle, 1998; Valle 2000; Andrade, 2001).

Além da participação em iniciativas do governo federal, há produções oriundas de colaboração com governos estaduais no desenvolvimento de avaliações de seus sistemas escolares, como no caso do Paraná (Vianna, Gatti, 1988); de Fortaleza, Salvador, São Paulo e Curitiba (Vianna, 1991); de Minas Gerais (Vianna, 1992a); de São Paulo (Vianna, 1992b; Gatti, Novaes, Bizzocchi, 1994; Esposito, 2000) e do Rio Grande do Norte (Sousa, coord., 1997).

Dentre estes, o que teve maior divulgação, e possivelmente se constituiu em referência para outras redes de ensino, foi o Programa de Avaliação da Escola Pública de Minas Gerais, que teve sua concepção e condução orientadas por Heraldo Vianna. Seu delineamento e resultados podem ser conhecidos por meio de artigos publicados na revista Estudos em Avaliação Educacional, em 1992, e evidenciam um delineamento que se diferencia de outros programas, destacando-se, entre outros aspectos, os seguintes: visava subsidiar decisões e intervenções dos integrantes da rede pública, nas diversas instâncias do sistema - desde a administração central até as escolas; previa o envolvimento de professores e da comunidade escolar nas atividades avaliativas; propunha que a interpretação dos resultados de rendimento escolar tivesse como referência o contexto da escola e da cultura local e incluía atividades de auto-avaliação da escola.

É interessante registrar que algumas reflexões de pesquisadores da própria Fundação alertam sobre possíveis implicações dos delineamentos 
que usualmente vêm sendo adotados nas avaliações de sistema, que se constituem em contribuição relevante para a crítica, e eventuais redirecionamentos nas iniciativas em curso no país, que são a seguir mencionadas.

Philip Fletcher, em artigo que trata de propósitos da avaliação educacional, apresenta pertinentes ponderações de natureza técnica e política, aqui parcialmente reproduzidas. Tendo como referência experiências conduzidas em estados americanos de monitoramento do rendimento, comenta:

"Há diversos problemas com essa modalidade de avaliação. (...) na medida em que Estados e escolas não disponham do fôlego financeiro e competência técnica para gerenciar um sistema de monitoramento do desempenho com os novos recursos da informática, este seria um sistema a ser evitado. Uma segunda desvantagem pode ser o eventual estreitamento do currículo por escolas que tentam se adaptar aos sistemas de monitoramento do rendimento.(...)

Nem todo mundo tem condições de responder aos sinais do mercado preconizado pelo sistema de monitoramento. Exigências de residência no local reduzem as opções de escolha. (...) É duvidoso pressupor que as unidades deficientes tenham iguais oportunidades para responder aos incentivos e sanções de um sistema de monitoramento do rendimento. Pode ser, inclusive, que uma das conseqüências indevidas desse tipo de monitoramento seja a de exacerbar as diferenças cognitivas das comunidades ricas e pobres, urbanas e rurais, reforçando as disparidades sociais existentes." (1995, p.106)

Em artigo que analisa a produção acadêmica, divulgada em periódicos nacionais nos anos 90, Barretto, ao tratar da produção relativa a modelos e metodologias de avaliação em larga escala, destaca a função reguladora, lembrando sua importância e centralidade nas reformas educativas em curso em diferentes países. Comenta que a avaliação, nesse modelo:

“(...) permite não só a ampliação do controle do Estado sobre o currículo e as formas de regulação do sistema escolar, como também sobre os recursos aplicados na área. Nesse sentido, os imperativos da avaliação terminam por pressionar a formulação de currículos nacionais em países que nunca os tiveram, ou levam à sua reformulação e atualização nos que já os possuíam, visto que eles são a referência 'natural' para o emprego da aferição padronizada do rendimento escolar, instrumento privilegiado do modelo." (2000, p. 10) 
Maria Laura Franco, em artigo que trata de avaliação de cursos, constata a quantidade de programas e de iniciativas governamentais direcionados para a avaliação de rendimento quanto para avaliação de cursos, alertando que:

“... não podemos transpor linearmente para a Educação uma concepção de avaliação que se deixa pautar pelos pressupostos de 'qualidade total', de atribuição diferencial por mérito e pela acirrada competitividade. Isto porque estamos falando de uma realidade diferente daquela regida unicamente pelas exigências e regras do mercado." (2000, p.148)

Em publicação que trata de avaliações em larga escala, Vianna apresenta uma cuidadosa análise de iniciativas desencadeadas no contexto brasileiro, como o Sistema de Avaliação do ensino Básico (Saeb), o Exame Nacional do Ensino Médio (Enem) e o Exame Nacional de Cursos (ENC), contemplando aspectos técnicos e políticos inerentes a essas iniciativas, com propostas para seu aperfeiçoamento. Nos limites deste texto, citamos apenas um parágrafo que, espera-se, possa ilustrar a abrangência das contribuições trazidas pelo autor:

"A análise das grandes avaliações realizadas em território nacional, independentemente do nivel administrativo que as promova, leva-nos a alguns problemas complexos e de difícil solução, como os relacionados às escalas empregadas, ao tipo de instrumentação usado e aos julgamentos comparativos que são emitidos sem maiores considerações sobre suas implicações e conseqüências decorrentes das repercussões no ambiente educacional e suas extrapolações na sociedade." (2003, p.63)

As referências às produções que alertam sobre inconsistências metodológicas e/ou possíveis conseqüências educacionais e sociais de avaliações de sistemas são expressão do movimento de produção de conhecimento e de sua crítica, postura esperada de uma instituição de pesquisa, como é a Fundação.

Com enfoque sobre o rendimento escolar, mas com finalidade de analisar e problematizar concepções e práticas de avaliação de aprendizagem dos alunos, tal como tendencialmente se realizam na escola, há produções significativas embora em número reduzido, comparativamente às que se voltam à avaliação de rendimento com vistas à análise de sistemas educacionais. Embora na literatura educacional, dentre os objetos de avaliação, a aprendizagem do aluno seja o mais freqüentemente abordado, nos estudos de pesquisadores da Fundação 
mereceu menos ênfase. Na relação bibliográfica disponibilizada para análise, identificam-se as produções de Gatti (1987a); Davis, Esposito (1990); Sousa (org., 1991); Silva, Davis (1993); Barretto et al. (2001) e Gatti (2003).

\section{O POTENCIAL FORMATIVO DO CONHECIMENTO QUE VEM SENDO DIVULGADO}

Como já se evidenciou nas considerações apresentadas acerca dos focos mais expressivos presentes no conjunto da produção, a divulgação de aportes conceituais, sociopolíticos e/ou metodológicos acerca de medida e avaliação educacional tem sido constante, desde os estudos inicialmente direcionados à seleção de candidatos para o ensino superior. Tal prática merece ser destacada, pois se constitui em um caminho valioso de formação de educadores, interessados no desenvolvimento de estudos e pesquisas na área.

Essa constatação tem um significado especial, pois, no Brasil, o campo da avaliação vem sendo construído de modo informal e não sistemático, tendo como conseqüência, dentre outras, a carência de espaços de formação de educadores nessa área de investigação. Assim, a difusão de aportes presentes na literatura relativa à medida e avaliação educacional, bem como de reflexões, experiências e projetos desenvolvidos por pesquisadores da Fundação, especialmente por meio dos Cadernos de Pesquisa e Estudos em Avaliação Educacional, desempenham papel significativo no processo de formação, propiciando não só uma atitude de aceitação do que é proposto ou realizado, mas, também, suscitando questionamentos, por meio da socialização de diferentes posições, não só de pesquisadores da própria Fundação, mas, também, de outras instituições.

Nessa mesma direção, é oportuno mencionar seminários que foram promovidos pela Fundação, como, por exemplo, o de "Avaliação na escola de $1^{\circ}$ grau", em julho 1987, o de "Avaliação Institucional", em 1990 e o "Seminário Internacional sobre Modelos Avaliativos", em 1996.

\section{ÊNFASES PRESENTES NA INVESTIGAÇÃO NO DECORRER DOS 40 ANOS: UMA VISÃO SINTÉTICA}

No levantamento das publicações relativas à avaliação educacional, disponibilizadas pela Biblioteca da Fundação Carlos Chagas, os primeiros 
registros datam de 1972, estendendo-se, ininterruptamente até 2003. Para se ter uma visão geral dos focos de pesquisa privilegiados, e sua ênfase no decorrer dos 40 anos da Fundação Carlos Chagas, bem como dos pesquisadores ${ }^{5}$ que mais intensamente contribuíram, ou vêm contribuindo, para a produção e divulgação de conhecimento em relação a esses focos, organizou-se o quadro a seguir.

TENDÊNCIAS IDENTIFICADAS NA PRODUÇÃO: 1964 aos dias atuais

\begin{tabular}{|c|c|c|c|c|c|}
\hline Focos Períodos & $1964 / 1973$ & $1974 / 1983$ & $1984 / 1993$ & $1994 / 2003$ & $\begin{array}{l}\text { Principais autores das } \\
\text { produções divulgadas }\end{array}$ \\
\hline $\begin{array}{l}\text { Processos seleti- } \\
\text { vos/vestibular }\end{array}$ & - & & - & & $\begin{array}{l}\text { Adolpho RIBEIRO NETTO } \\
\text { Bernardete A. GATTI } \\
\text { Carmen L. M. BARROSO } \\
\text { Heraldo M. VIANNA }\end{array}$ \\
\hline $\begin{array}{l}\text { Avaliação curri- } \\
\text { cular - programas } \\
\text { e projetos }\end{array}$ & & & & & $\begin{array}{l}\text { Clarilza P. de SOUSA } \\
\text { Maria Amélia A. GOLDBERG } \\
\text { Maria Laura P. B. FRANCO }\end{array}$ \\
\hline $\begin{array}{l}\text { Avaliação de polí- } \\
\text { ticas educacionais } \\
\text { - programas e } \\
\text { projetos }\end{array}$ & & & & & $\begin{array}{l}\text { Bernardete A. GATTI } \\
\text { Clarilza P. de SOUSA } \\
\text { Elba S. S. BARRETTO } \\
\text { Heraldo M. VIANNA } \\
\text { Teresa Roserley N. da SILVA }\end{array}$ \\
\hline $\begin{array}{l}\text { Avaliação de } \\
\text { rendimento } \\
\text { escolar }\end{array}$ & & - & & & $\begin{array}{l}\text { Bernardete A. GATTI } \\
\text { Clarilza P. de SOUSA } \\
\text { Cláudia DAVIS } \\
\text { Gláucia T. FRANCO (Novaes) } \\
\text { Heraldo M. VIANNA } \\
\text { Philip R. FLETCHER } \\
\text { Raquel da Cunha VALLE } \\
\text { Teresa Roserley N. da SILVA } \\
\text { Yara L. ESPOSITO }\end{array}$ \\
\hline
\end{tabular}

5 Considerando a extensa produção e a impossibilidade de relacioná-la integralmente nos limites deste texto, recorreu-se à menção de alguns autores, o que possibilita aos interessados a localização de títulos de referência sobre os focos de avaliação educacional destacados. 
Tendo em conta os trabalhos divulgados, identificam-se claramente quatro tendências dominantes ao longo do tempo:

- das primeiras publicações até meados de 1980, os trabalhos são, em maior número, direcionados à medida educacional, tratando de processos seletivos/vestibular;

- de meados dos anos de 1970 até início da década de 1980 há, concomitantemente, publicações acerca de avaliação de programas e projetos, no campo da avaliação de currículo;

- a partir de meados de 1985, há publicações relativas à avaliação de políticas educacionais, por meio de apreciação de programas e projetos específicos;

- a partir dos anos iniciais da década de 1980, têm início as publicações que se voltam à avaliação de rendimento escolar, tratando de aspectos relativos à medida de desempenho, exclusivamente ou de modo associado à avaliação de sistemas educacionais, situando-se aí o maior volume de publicações.

\section{INDAGAÇÕES E PERSPECTIVAS DE PRODUÇÃO NA ÁREA}

A retrospectiva histórica da produção da Fundação Carlos Chagas no campo da medida e avaliação educacional, aqui apresentada, permite explicar o título dado a este texto, ou seja, evidencia a liderança, pioneirismo e influência de seus pesquisadores na constituição deste campo de estudo no Brasil. Assim, revisar a produção significa apreender caminhos trilhados no campo da avaliação educacional, no passado e no presente. E, o que esperar do futuro?

Para responder a esta indagação, Heraldo Vianna, um dos pesquisadores da Fundação, assim se posiciona ao falar sobre o futuro da avaliação:

“O que acontecerá (...) podemos, a partir das tendências atuais, pressentir que, em nível de escola e mesmo de sistema de ensino, a avaliação se concentrará enfaticamente no uso de instrumentos de medida, especialmente para a tomada de decisões administrativas. É possível, entretanto, que, com o treinamento de avaliadores, formas alternativas de avaliação venham a surgir (avaliação individualizada, qualitativa), a médio prazo, especialmente se instituições especializadas se dedicarem à pesquisa e à avaliação.(...)

O que deve acontecer? - acreditamos que, se a idéia de avaliação prosperar e se essa área passar a ter um caráter interdisciplinar, trabalhando em conjunto com outras ciências do homem, a sua produção passará a exigir um trabalho conexo, 
indispensável ao seu desenvolvimento, ou seja, a avaliação da avaliação, que pode ser expressa simplesmente pela palavra metavaliação. Ao lado disso, a prática da avaliação gerará, certamente, a necessidade de estudos conceituais e empíricos sobre a avaliação (...) a avaliação será uma área de pesquisa.(...)

Quando pensamos sobre o que pode acontecer, imaginamos, sob o risco de sermos temerários, que a escola saberá julgar potencialidades não exploradas da avaliação; que a pesquisa sobre avaliação não será episódica, mas terá uma linha contínua de seguimento, e que não apenas a avaliação, mas, também, a própria pesquisa da avaliação serão temas prioritários para os governos e as agências financiadoras de projetos." (2000, p.169)

Essa manifestação traz desafios e perspectivas aos educadores, particularmente aos que se interessam ou se dedicam a esse campo de estudo e pesquisa. As respostas a serem construídas, no entanto, podem ser diversificadas, tendo em conta fatores epistemológicos, políticos e sociais, ou seja, tanto se pode caminhar em direção a uma avaliação a serviço do controle quanto em direção à avaliação a serviço da emancipação, com impactos sociais, políticos e educacionais distintos.

Certamente, para impulsionar, no Brasil, a construção de propostas e respostas capazes de colocar a avaliação a serviço do direito de todos a uma educação de qualidade, continuarão sendo importantes os estudos e pesquisas da Fundação nesse campo.

\section{REFERÊNCIAS BIBLIOGRÁFICAS}

ANDRADE, D. F. Desempenhos de grupos de alunos por intermédio da Teoria da Resposta ao Item. Estudos em Avaliação Educacional, n.23, p.31-69, jan./jun. 2001.

ANDRADE, D. F.; VALLE, R. C. Introdução à Teoria da Resposta ao Item. Estudos em Avaliação Educacional, n.18, p.32, jul./dez. 1998.

APRESENTAÇÃO. Estudos em Avaliação Educacional, n.1, p.3, jun./dez. 1990.

BARRETTO, E. S. S. A Avaliação na educação básica: entre dois modelos. Trabalho apresentado no GT Estado e Política Educacional da ANPEd, $24^{\mathrm{a}}$ Reunião Anual, set. 2000, Caxambu, p.10. 
BARRETTO, E. S. S.; PINTO, R. P. (orgs.). Avaliação do programa “Um Salto para o Futuro": estudo piloto do impacto. São Paulo: FCC, 1997.

BARRETTO, E. S. S. et al. Avaliação na educação básica nos anos 90 segundo os periódicos acadêmicos. Cadernos de Pesquisa, n.114, p.49-88, nov. 2001.

BARROSO, C. L. M. Estudos de predição do comportamento acadêmico: Faculdade de Medicina. Cadernos de Pesquisa, n.5, p.55-76, abr. 1973.

CUNHA, L. A. Os (Des)caminhos da pesquisa na pós-graduação em educação. In: SEMINÁRIO SOBRE A PRODUÇÃO CIENTÍFICA NOS PROGRAMAS DE PÓS-GRADUAÇÃO EM EDUCAÇÃO. Anais do... Brasília: MEC, 1979. p. 3-15.

DAVIS, C. Vida e escola Severina: um estudo da prática pedagógica em uma escola rural do Piauí. São Paulo, 1988. Tese (dout.) USP/FE.

DAVIS, C.; DIETZSCH, M. J. M. Avaliação da educação básica no nordeste brasileiro: estudo do rendimento escolar na zona rural. Cadernos de Pesquisa, n.46, p.5-55, ago. 1983.

DAVIS, C.; ESPOSITO, Y. L. A Escola pública: um estudo sobre aprendizagem nas séries iniciais. Estudos em Avaliação Educacional, n.5, p.2950, jan./jun. 1992.

Papel e função do erro na avaliação escolar. Cadernos de Pesquisa, n.74, p.71-75, ago. 1990.

206, maio/ago. 1991.

Revista Brasileira de Estudos Pedagógicos, v.72, n.171, p.196-

ESPOSITO, Y. L. Estudo analítico de uma experiência de avaliação do impacto de políticas de melhoria da qualidade do ensino. São Paulo, 1996. Tese (dout.) PUC/SP.

ESPOSITO, Y. L. (coord.). Sistema de avaliação de rendimento escolar do Estado de São Paulo - SARESP 98: conhecendo os resultados da avaliação. São Paulo: FDE, 2000.

ESPOSITO, Y. L.; FRANCO, G. T. Avaliação do rendimento escolar dos alunos das escolas-padrão - $1^{a}$ etapa: $8^{a}$ série. São Paulo: FCC/DPE, 1992. 
FLETCHER, P. R. Propósitos da avaliação educacional: uma análise das alternativas. Estudos em Avaliação Educacional, São Paulo, n.11, p.93-112, jan./jun. 1995.

Teoria da resposta ao item: medidas invariantes do desempenho escolar. Ensaio: Avaliação e Políticas Públicas em Educação, v.1, n.2, p. 21-8, jan./mar. 1994.

FRANCO, M. L. P. B. A Prática da avaliação de cursos. Estudos em Avaliação Educacional, n.21, p.147-166, jan./jun. 2000.

FUNDAÇÃO CARLOS CHAGAS. Avaliação do processo de implementação e do impacto das ações do projeto de educação continuada da Secretaria de Estado da Educação: $1^{\circ}$ relatório de andamento. São Paulo: FCC/NAE, 1997.

FUNDAÇÃO CARLOS CHAGAS. Avaliação do processo de implementação e do impacto das ações do projeto de educação continuada da secretaria de estado da educação: $2^{\circ}$ relatório de andamento. São Paulo: FCC/NAE, 1998.

PROMED: avaliação externa do programa de melhoria e expansão do ensino médio no Estado de São Paulo. Relatório intermediário: estudos de caso e representações sociais. São Paulo: FCC, 2003.

GATTI, B. A. Avaliação educacional no Brasil: experiências, problemas, recomendações. Estudos em Avaliação Educacional, n.10, p.67-80, jul./dez. 1994.

GATTI, B. A. Enfrentando o desafio da escola: princípios e diretrizes para a ação. Cadernos de Pesquisa, n.85, p.5-10, maio 1993.

O Professor e a avaliação em sala de aula. Estudos em Avaliação Educacional, n.27, p.97-114, jan./jun. 2003.

O Rendimento escolar em distintos setores da sociedade. Estudos em Avaliação Educacional, n.7, p.95-112, jan./jun. 1993a.

A Reprovação na $1^{a}$ série do $1^{\circ}$ grau: um estudo de caso. Cadernos de Pesquisa, n.38, p.3-13, ago. 1981.

Retrospectiva da pesquisa educacional no Brasil. Revista Brasileira de Estudos Pedagógicos. Brasília, v.68, n.159, p.279-288, maio/ago. 1987. 
GATTI, B. A. Testes e avaliações do ensino no Brasil. Educação e Seleção, n.16, p.33-42, dez. 1987a.

GATTI, B. A. (coord.). Avaliação da dimensão qualidade no contexto do projeto EDURURAL: estudo de caso: a escola rural num município do interior nordestino. São Paulo: FCC/ DPE, 1981.

Proposta de Avaliação do impacto da jornada única na Região Metropolitana de São Paulo. São Paulo: FCC/DPE, 1990.

GATTI, B. A.; NOVAES, G. T. F.; BIZZOCCHI, M. Programa de avaliação educacional - SEESP: relatório final. São Paulo: FCC, 1994.

GATTI, B. A.; VIANNA, H. M.; DAVIS, C. Problemas e impasses da avaliação de projetos e sistemas educacionais: dois casos brasileiros. Estudos em Avaliação Educacional, n.4, p.7-27, jul./dez. 1991.

GOLDBERG, M. A. A. Avaliação e planejamento educacional: problemas conceituais e metodológicos. Cadernos de Pesquisa, n.7, p.61-72, jun. 1973.

GOLDBERG, M. A. A.; BARRETTO, E. S. S.; MENEZES, S. M. Avaliação educacional e educação de adultos. Cadernos de Pesquisa, n.8, p. 5-110, set. 1973.

GOLDBERG, M. A. A.; FRANCO, M. L. P. B. Inovação educacional: um projeto controlado por avaliação e pesquisa. São Paulo: Cortez \& Moraes; FCC/DPE, 1980.

GOldBERG, M. A. A.; SOUSA, C. P. A Prática da avaliação. São Paulo: Cortez \& Moraes, 1979.

(orgs.). Avaliação de programas educacionais: vicissitudes, controvérsias, desafios. São Paulo: EPU, 1982.

GOUVEIA, A. J. Algumas reflexões sobre a pesquisa educacional no Brasil. Revista Brasileira de Estudos Pedagógicos. Rio de Janeiro, v. 60, n. 136, p.496499, out./dez. 1974.

Pesquisa educacional no Brasil. Cadernos de Pesquisa, São Paulo, n.1, p.1-48, jul. 1971. 
GROSBAUM, M. W. et al. Projeto CEFAM: avaliação do percurso. São Paulo: SEE, 1992.

LESER, W. S. P. As Origens do vestibular unificado. Educação e Seleção, n.11, p.3-8, jun. 1985.

MARTINS, A. M. Avaliando um programa de governo: a voz dos atores. Ensaio: Avaliação e Políticas Públicas em Educação, v.7 n.24, p.309-336. jul./set. 1999.

ORLANDI, L. B. L. O problema da pesquisa em educação e algumas de suas implicações. Educação Hoje, n.2, p.7-25, abr. 1969.

RIBEIRO NETTO, A. Considerações sobre avaliação educacional. Educação $e$ Seleção, n.5, p.5-7, jul. 1982.

SANCHEZ, V. F. Apresentação. Educação e Seleção, n.1, p.5-7, jul.1980.

Editorial. Educação e Seleção, n.2, p.3, dez. 1980.

SAUL, A. M. Avaliação emancipatória: desafio à teoria e à prática de avaliação e reformulação de currículo. São Paulo: Cortez; Autores Associados, 1988.

SILVA, T. R. N. Classes de aceleração: mais de 100 mil alunos da rede estadual paulista recuperem o atraso escolar. Em aberto, v.17, n.71, p.129-33, jan. 2000.

SILVA, T. R. N.; DAVIS, C. Proibido repetir. Estudos em Avaliação Educacional, n.7, p.5-44, jan./jun. 1993.

SILVA, T. R. N.; ESPOSITO, Y. L. (coords.). Avaliação do processo de inovações no ciclo básico e seu impacto sobre a situação de ensino-aprendizagem na região metropolitana de São Paulo: relatório técnico, 12. São Paulo: SEE; FCC/ DPE, 1995.

SOUSA, C. P. Descrição de uma trajetória na/da avaliação educacional. Idéias, n.30, p.161-174, 1998.

SOUSA, C. P. (coord.). Avaliação das escolas estaduais de ensino fundamental e ensino médio. São Paulo: FCC/DPE/ NAE, 1997. 
SOUSA, C. P. (org.) Avaliação do rendimento escolar. Campinas: Papirus, 1991.

SOUSA, S. M. Z. L. Avaliação da aprendizagem: natureza e contribuições da pesquisa no Brasil, no período de 1980 a 1990. São Paulo, 1994. Tese. (dout.) USP/FE.

VALLE, R. C. Construction and interpretation of knowledge scales: a case study. In: FUNDAÇÃO CESGRANRIO. The Future and challenges of educational assessment in the $21^{\text {st }}$ Century. Rio de Janeiro, 2001. v.1.

Teoria da resposta ao item. Estudos em Avaliação Educacional, n.21, p.7-91, jan./jun. 2000.

VIANNA, H. M. Avaliação do desempenho em matemática e ciências: uma experiência em São Paulo e em Fortaleza. Estudos em Avaliação Educacional, n.5, p.107-120, jun./dez. 1992b.

Avaliação do rendimento de alunos de escolas do $1^{\circ}$ grau da rede pública: um estudo em 39 cidades. Educação e Seleção, n.20, p.5-56, dez. 1989.

Avaliação do rendimento de alunos de escolas do $1^{\circ}$ grau da rede pública: um estudo em 20 cidades. Educação e Seleção, n.19, p.33-98, jun. 1989a.

Avaliação do rendimento escolar de alunos da $3^{\mathrm{a}}$ série do $2^{\circ}$ grau: subsídios para uma discussão. Estudos em Avaliação Educacional, n.3, p.71102, jan./jun. 1991.

Avaliação educacional: problemas gerais e formação do avaliador. Educação e Seleção, n.5, p.9-14, jul. 1982.

Ibrasa, 2000.

Avaliação educacional: teoria, planejamento, modelos. São Paulo:

Avaliação educacional: uma perspectiva histórica. Estudos em Avaliação Educacional, n.12, p.7-24, jul./dez. 1995.

Avaliação educacional: vivência e reflexão. Estudos em Avaliação Educacional, n.18, p.69-109, jul./dez. 1998. 
VIANNA, H. M. Avaliação educacional nos Cadernos de Pesquisa. Cadernos de Pesquisa, n.80, p.100-105, fev. 1992.

Avaliações nacionais em larga escala: análises e propostas. Estudos em Avaliação Educacional, n.27, p.41-76, jan./jun. 2003.

Desempenho dos alunos do ciclo básico de alfabetização em Minas Gerais: análise dos resultados e identificação de pontos críticos. Estudos em Avaliação Educacional, n.6, p. 61-93, jul./dez. 1992a.

Impactos dos testes sobre os sistemas e objetivos educacionais: a experiência brasileira. Cadernos de Pesquisa, n.27, p.69-71, dez. 1978.

Testes em educação. São Paulo: Ibrasa, 1973.

VIANNA, H. M.; FRANCO, G. T. Avaliação do rendimento de alunos de escolas do $1^{\circ}$ grau da rede privada: pontos críticos e convergências. Estudos em Avaliação Educacional. São Paulo, n. 7, p. 113-131, jan./jul. 1993.

VIANNA, H. M.; GATTI, B. A. Avaliação do rendimento escolar de alunos das $2^{\mathrm{a}} \mathrm{s}$ e $4^{\mathrm{a}} \mathrm{s}$ séries de escolas oficiais do Estado do Paraná. Educação e Seleção, n.18, p.5-63, dez. 1988.

Recebido em: outubro 2004

Aprovado para publicação em: dezembro 2004 
